\title{
Is Cancer Immune from Partisan Polarization? How Partisan Identity Motivates Opposition to Preventative Cancer Vaccination in the U.S.
}

Matt Motta. Assistant Professor. Dept. of Political Science. Oklahoma State University.

matthew[dot]motta[at]okstate[dot]edu

As one of the leading causes of death in the United States, cancer impacts the lives of Democrats, Republicans and Independents alike. Correspondingly, we might expect experimental cancer preventatives to be more-or-less "immune" to partisan polarization. Experiences with the deadly COVID-19 pandemic, however, suggest that even amid an unprecedented public health threat, some Americans were nevertheless motivated by political partisanship - particularly on the ideological right to reject life-saving preventatives. In this study, I investigate whether tying partisan accomplishments in funding cancer prevention research to vaccine development might influence public acceptance of "personalized cancer vaccines," which prevent the onset of cancer using tumor detection and mitigation mechanisms informed by one's DNA. In a pre-registered analysis plan and survey experiment, I find that Republicans are less likely (in the absence of elite cues) to intend to receive personalized cancer vaccines and/or recommend that others do the same. Experimentally, I find that when respondents are exposed to information wherein Democrats claim credit for taking action to fund cancer research, polarization tends to increase; such that Republicans become even less likely to intend to receive a vaccine. I conclude by discussing how these findings can motivate effective political communication aimed at resolving one of the greatest public health crises of our time.

In a typical year, an estimated 1.8 million Americans will receive a new cancer diagnosis. Over 600 thousand will ultimately die from the disease. Efforts to prevent the onset of cancer cancer, a lofty objective that (former) Vice President Biden likened to President Kennedy's promise to put human beings on the moon (Naher 2016; Sharpless \& Singer 2021), may now be achievable through the use of what are known as "personalized cancer vaccines."

Although the science underlying how cancer vaccines work is quite complex, personalized cancer vaccines are designed to prevent the onset of cancer via a two-step process (Blass \& Ott 2021). First, for people who both (1) have a tumor, and (2) are at risk of developing cancer, medical professionals sequence the tumor's genetic makeup. The vaccine then provides the body with this genetic information, which is used to both identify the tumor and stimulate a mitigating immune response.

One difficulty a personalized cancer vaccine might face is the possibility that demand for the vaccine will be influenced by partisan identity and political disagreement. Indeed, past research has documented that negative attitudes and misinformation about childhood vaccine safety (Oliver \& Wood 2014; Nyhan et al., 2014), which has been shown to motivate opposition to vaccination (Jolley \& Douglas 2014), is particularly common on the ideological right (e.g., Joslyn \& Sylvester 2018; Motta 2021) . Americans' willingness to receive life-saving vaccines produced in response to the COVID-19 pandemic -- which, in 2020, was responsible for nearly as many deaths than all cancers combined in the US (Fauzia 2021) -also faced strong levels of opposition on the ideological right (Vinswath et al., 2020; Callaghan et al., 
2021), like many other pro-social and protective health behaviors (e.g., mask wearing and physical distancing; see: Grossman et al., 2020; Gadarian et al., 2021).

Health politics researchers might therefore ask whether or not a cure for cancer is immune to partisan vaccine disagreement. Or is it -- like America's public health response to a deadly global pandemic -likely to succumb to the increasingly-polarized nature of political debates in American public life?

In this paper, I aim to test these questions by assessing whether attributing FDA approval of a personalized cancer vaccine to partisan elites who might seek to claim credit for (or otherwise be linked to) vaccine development might politicize views toward vaccine uptake. In a novel and pre-registered survey experiment, I find that -- although self-identified Republicans are less supportive of personalized cancer vaccines than self-identified Democrats in the absence of elite partisan cues -- mentioning Democratic political elites' efforts to fund cancer research further encourages opposition among Republicans. Linking Republican elites to the vaccine improves vaccine uptake on the right, but does not erase baseline differences in partisans' willingness to receive or recommend vaccination to others.

These results provide a direction for effective political and health communication about personalized cancer vaccines. If and when these life-saving therapeutics are developed they, presumably, will be under the purview of an FDA overseen by either a Democratic or Republican presidential administration. Politicians on both the right and the left might also seek to claim credit for enabling the research that ultimately leads to vaccine development. My work cautions that it is essential that politicians avoid claiming credit for, or otherwise tying their name (and, more importantly, partisan reputation), to these achievements. Claiming credit, however warranted, may create an incentive for partisan backlash.

\section{Are Cancer Vaccines Immune from Partisan Motivated Reasoning?}

American politics has grown intensely divisive in recent years. As our allegiances to the two parties in Washington have become increasingly-central components of our social identities and senses of self (Mason 2018; West \& lyengar 2020), Americans have come to let their partisan loyalties govern the sources of political information that they find trustworthy (Stroud 2011; Petersen et al., 2021), influence the stances they hold on salient policy issues (Lenz 2013; Mason 2015), and motivate feelings of ill-will toward those with whom they disagree (lyengar et al., 2019; Webster 2020).

The degree to which Americans agree about established political and scientific facts has also grown more contentious in recent years (see: Jerit \& Zhao 2020 for a review). For example, throughout the deadly COVID-19 pandemic -- which claimed the lives of over 600 thousand Americans at the time of this writing and caused major disruptions to everyday social life -- self-identified Republicans were less likely to believe that FDA approved COVID-19 vaccines were safe and effective ways to prevent infection, more likely to reject trustworthiness of public health advice from medical and scientific experts, and more likely to believe that the pandemic's public health risks had been exaggerated (Motta et al., 2020; Miller 2020; Enders et al., 2020; Callaghan et al., 2021). 
Correspondingly, self-identified Republicans were less likely to intend to vaccinate against COVID-19 even amid unprecedented public health threat; putting both themselves and others at risk of infection. The entanglement between partisan identity and differential exposure to right-leaning news sources (which were less likely than mainstream sources to feature accurate information about the pandemic; see: Jaimeson \& Alberracain 2020; Motta et al., 2020; Stecula \& Pickup 2020), longstanding concerns about personal freedoms to forego taking action to protect others (Amin et al., 2017; Motta \& Goren 2021), distrust in scientific authorities (Gauchat 2012; Motta 2018; Merkley \& Loewen 2021; Sturgis et al., 2021; Lindholt et al., 2021) and religious/moral preferences for bodily sanctity (Clifford \& Wendell 2016; Lunz-Trujillo et al., 2020; Garcia \& Yap 2021), can all jointly help explain why Republicans were more likely to reject not only the COVID-19 vaccine, but to harbor suspicion about the safety and efficacy of childhood vaccines more broadly .

There is therefore good reason to believe that -- although cancer touches the lives of Democrats, Republicans, and Independents alike, and while previous public opinion studies find that support for funding cancer research is relatively high on both the left and the right (Schattner 2015) -- even a personalized cancer vaccine may not be able to escape the grip of partisan disagreement. Republicans, compared to Democrats or Independents, should therefore be less likely to (a) intend to vaccinate and (b) recommend that others pursue vaccination via a personalized cancer vaccine $(\mathrm{H} 1)$.

Mentioning the role that partisan political figures play in the vaccine approval process may further motivate opposition to vaccine uptake, for several reasons. For example, regulatory government agencies -- like the FDA -- necessarily fall under the jurisdiction of the current president. Although these agencies are not necessarily themselves political, examples of regulators being influenced by political pressures have become recently salient in American politics; e.g., appointees from the Trump administration issuing statements on behalf of the FDA that, consistent with the administration's political objectives, shared misleading data about treatments for COVID-19 (Diamond 2020).

More generally, simply associating a regulatory agency with the current president may inspire partisans to engage in motivated reasoning (Kunda 1990; Kraft et al., 2015; Kahan 2017), whereby some allow their like or dislike of the president to color their views of those agencies' policies and regulations; e.g., an increased propensity to associate FDA decisions with other administrative actions deemed unfavorable, or to generate counter-arguments casting doubt on regulators' scientific credentials.

Adding the the possibility of motivated vaccine rejection is the fact that several politicians have established reputations regarding their willingness to fund cancer prevention research, and might therefore be motivated to either take or be attributed credit for vaccine developments.

On the left, President Biden is perhaps one of the best known cancer research advocates in the U.S. (McCarthy 2016; Kaiser \& Couzin-Frankel 2016) As Vice President, Biden was tapped to lead former President Obama's "moonshot" initiative to fund research aimed at curing cancer. Having experienced the loss of his son Beau to brain cancer, Biden vocally prioritized the importance of funding efforts to cure cancer. Partisans aware (or made aware) of the Biden family's experiences with the disease, and the 
(now) president's highly public involvement with efforts to cure cancer, might further engender Republican opposition to personalized cancer vaccines that could deliver on that promise.

On the right, Republicans like Fred Upton (R-MI) have also been consistent and strong supporters of efforts to fund cancer research. Upton proved critical, for example, in establishing a legislative funding mechanism for President Obama's "moonshot" initiative. Upton introduced legislation -- the 21st Century Cures program -- which enabled the initiative to be codified into law, and worked with politicians on both sides of the partisan aisle to provide over $\$ 6$ billion in federal support for cancer research (Karlin-Smith 2016).

Taken together, this line of reasoning suggests that attributing the development of a safe and effective personalized cancer vaccine to Democratic elites like Joe Biden might further exacerbate vaccine attitude polarization on the right ( $\mathrm{H} 2 \mathrm{a}$ ). Given Republicans' potentially-greater cancer vaccine skepticism (H1), I

further suspect that elite Republican elites like Fred Upton neutralize polarization (H2b), either by (RQ1) increasing vaccine support among Republicans and/or (RQ2) by diminishing it among Democrats.

Of course, whether or not these anticipated patterns of results accurately characterize how partisans think about personalized cancer vaccines is, of course, an open question. Personalized cancer vaccines do not presently have broad regulatory approval, and have received relatively little attention in the popular press. Correspondingly, in what follows, I outline a first-of-its-kind experimental procedure for testing my theoretical expectations about personalized cancer vaccine uptake.

\section{Experimental Procedure}

I test my aforementioned expectations via a $2 \mathrm{X} 1$ experimental design embedded in a public opinion survey. As detailed in Table 1, respondents were first be assigned to read identical passages explaining what personalized cancer vaccines are, and how they work. Respondents were then assigned to receive information portraying the funding for vaccine development as the result of either bi-partisan (the control condition) or partisan ("Democrats like President Biden," "Republicans like Fred Upton (R-MI)") efforts to fund vaccine research. Afterwards, they will answer two questions (listed in Table 1) about their views toward cancer vaccination.

Some might argue that employing President Biden (a household name) as a Democratic cue vs. Fred Upton (a lesser-known Representative) might lead to partisan imbalance in treatment effects across conditions. While I of course cannot create a coterminous Republican president who shares Biden's passion for cancer research, I could theoretically swap out Biden's name for that of a lesser-known Democrat. Doing this, however, would potentially come at the cost of external validity for the experimental design; as Biden is, as discussed above, one of the most prominent cancer advocates in Washington. Excluding him from conversations about funding may therefore strike some readers as suspicious or problematic. Instead, I make an effort to standardize language about each politician's contributions to cancer research using nearly-identical language (see: Table 1); highlighting both as playing an essential role in facilitating a "federal moonshot initiative" to spearhead cancer research. 
While imperfect, my hope is that this approach at least offers a fair balance of internal and external validation considerations.

Table 1. Experimental Treatment Design \& Outcome Variable Information

\begin{tabular}{|c|c|c|c|}
\hline & Bi-Partisan & Democratic Cue & Republican Cue \\
\hline Preamble & \multicolumn{3}{|c|}{$\begin{array}{l}\text { As you may have heard, medical researchers are making substantial progress toward } \\
\text { developing personalized cancer vaccines. Personalized cancer vaccines can prevent people } \\
\text { from developing several common forms of cancer; such breast and lung cancer. } \\
\text { If deemed safe and effective in clinical trials, personalized cancer vaccines could be } \\
\text { administered to people at high risk of developing cancer. Because no two tumors are exactly } \\
\text { the same, personalized cancer vaccines work by first identifying tumors' genetic makeup, } \\
\text { and then train the body's immune system to stop the growth of those tumors. }\end{array}$} \\
\hline Manipulation & $\begin{array}{l}\text { Personalized cancer } \\
\text { vaccines would not be } \\
\text { possible without federal } \\
\text { funding championed by } \\
\text { both Democrats and } \\
\text { Republicans in } \\
\text { Congress, who have } \\
\text { made efforts to cure } \\
\text { cancer an important } \\
\text { health policy goal. }\end{array}$ & $\begin{array}{l}\text { Personalized cancer } \\
\text { vaccines would not be } \\
\text { possible without federal } \\
\text { funding championed by } \\
\text { Democrats like President } \\
\text { Biden, who headed a } \\
\text { federal "moonshot" } \\
\text { initiative to support cancer } \\
\text { research, and has made } \\
\text { curing cancer an important } \\
\text { health policy goal. }\end{array}$ & $\begin{array}{l}\text { Personalized cancer vaccines } \\
\text { would not be possible without } \\
\text { federal funding championed } \\
\text { by Republicans like Fred } \\
\text { Uptown (R-MI), who } \\
\text { introduced legislation critical } \\
\text { to funding a federal } \\
\text { "moonshot" initiative to } \\
\text { support cancer research, and } \\
\text { has made curing cancer an } \\
\text { important health policy goal. }\end{array}$ \\
\hline $\begin{array}{l}\text { Outcome } \\
\text { Variable } \\
\text { Measurement }\end{array}$ & \multicolumn{3}{|c|}{$\begin{array}{l}\text { If, in the next few years, the Food and Drug Administration were to determine that } \\
\text { personalized cancer vaccines are both safe and effective at preventing cancer, to what } \\
\text { degree would you be willing to do each of the following? } \\
\text { A. Receive a vaccine yourself, if deemed "at risk" of developing cancer by a medical } \\
\text { professional. } \\
\text { B. Encourage friends and family members to receive a vaccine, if deemed "at risk" of } \\
\text { developing cancer by a medical professional. } \\
\qquad 1>\text { Almost Certainly Would; }<2>\text { Very Likely Would; }<3>\text { Somewhat Likely Would; } \\
\quad<4>\text { Somewhat Likely Would Not; }<5>\text { Very Likely Would Not; }<6>\text { Almost Certainly } \\
\text { Would Not }\end{array}$} \\
\hline Expectation & $\begin{array}{l}\text { Moderate Partisan } \\
\text { Polarization (H1a-b). }\end{array}$ & $\begin{array}{l}\text { Strong Partisan Polarization } \\
(\mathrm{H} 2 \mathrm{a}) \text {. }\end{array}$ & $\begin{array}{l}\text { Weak or Neutralized Partisan } \\
\text { Polarization (H2b, RQ1-2) }\end{array}$ \\
\hline
\end{tabular}

\section{Data, Measures, \& Pre-Registered Analytic Procedure}

Data for this study come from a large online survey of $\mathrm{N}=1,959$ US adults (Completion Rate $=81 \%$, fielded between September 7-8 2021). Respondents were recruited to participate in the study via Lucid Theorem; a large, online, opt-in sampling platform that uses quota sampling to approximate national demographic benchmarks on respondents' age, race, gender, household income, educational attainment, and political partisanship. Lucid data has been used extensively in the study of US health politics and vaccine attitudes (e.g., Lunz-Trujillo et al., 2020; Uscinski et al., 2020; Miller 2020; Motta 
2021; Callaghan et al., 2021), and has been shown to both closely mirror nationally representative demographic benchmarks and recover well-studied experimental effects (Coppock \& McClellan 2019; Peyton et al., 2021).

Recognizing concerns about inattentiveness in the online survey-taking environment (Aronow et al. 2020), respondents completed both CAPTCHA verification prior to completing the survey (to eliminate the possibility of user-written scripts auto-completing surveys), and will be assigned to answer an attention check question at a randomly assigned spot in the survey. Additionally, I exclude from analysis those who may have engaged in excessive survey satisficing (Krosnick 1991) by removing respondents who finished the survey in less than one third of the anticipated completion time (5 out of 15 minutes).

I measure baseline levels of partisan disagreement about cancer vaccination ( $\mathrm{H} 1$ ) by plotting mean levels of vaccine acceptance across both ordinal outcome variables listed in Table 1 in the control condition (i.e., to avoid the possibility of experimental contamination effects). I assess these differences via both substantive (i.e., graphical presentation of means) and statistical difference-of-means comparisons (i.e., by assessing overlap in $95 \%$ confidence intervals across partisan groups).

To test for experimental treatment effects $(\mathrm{H} 2 \mathrm{a}-\mathrm{b})$, I then regress each ordered outcome variable (using ordered logistic regression) on dichotomous indicators of assignment to each of the partisan cue experimental conditions, with the control group serving as an omitted analytic baseline. I interact each dichotomous indicator with a standard seven-point measure of partisan identification, and assess treatment effects, across conditions, at each level of the party identification scale.

To ensure sufficient balance of experimental treatment assignment across partisan and other basic demographics (e.g., age, race, gender, educational attainment), I will include formal balance tests in the supplementary materials. In the event that any demographic factors are over-represented in one experimental condition relative to others, I will re-run the models described above controlling for those factor(s) as covariates. For robustness, I will also re-analyze the interactions between partisan identification and experimental treatment assignment across the full range of the partisan identity scale (i.e., treating it as a linear effect; rather than a series of potentially non-linear effects).

\section{Results}

Partisan Asymmetries in Vaccine Uptake \& Vaccine Recommendation.

I begin this analysis by assessing whether or not self-identified Republicans are less likely to intend to receive personalized cancer vaccines themselves $(\mathrm{H} 1 \mathrm{a})$, if deemed necessary by a medical professional, and/or ( $\mathrm{H} 1 \mathrm{~b})$ to recommend that friends and family members do the same. As noted in the pre-registered analysis plan, the top half of Figure 1 tests this possibility by presenting average scores (shaded bars) on the six-point scales summarized in Table 1 across PID, with 95\% confidence intervals extending outward from each one. Analyses are restricted to the control group, as to avoid the possibility of anticipated (i.e., H2) experimental contamination effects. 
The results offer support for both $\mathrm{H} 1 \mathrm{a}$ and $\mathrm{H} 1 \mathrm{~b}$. I find that average levels of vaccine refusal for both oneself and others tends to increase (albeit somewhat non-monotonically) as respondents more strongly self-identify with the Republican Party. Specifically, strong Republicans' average levels of vaccine refusal for both themselves ( $M=3.08,[2.79,3.59])$ and others $(M=3.17,[2.87,3.48])$, are significantly higher than those of self-identified strong Democrats ( $M=2.44,[2.22,2.67])$.

\section{Figure 1. Univariate and Multivariate Differences in Personalized Cancer Vaccine Uptake \& Recommendation by PID}

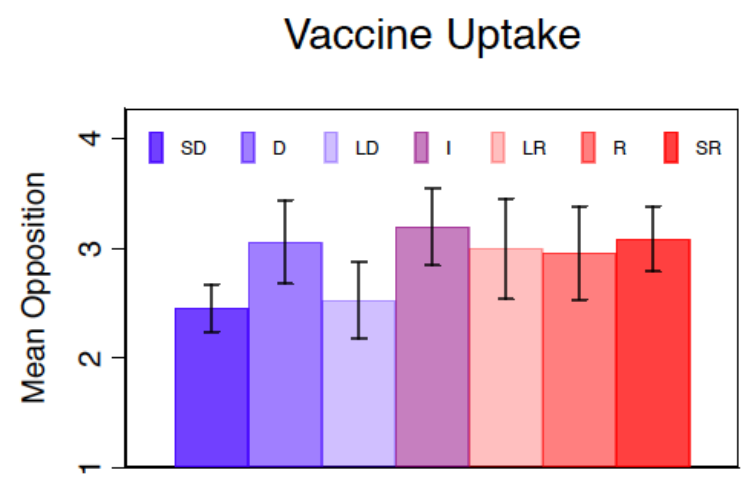

Vaccine Uptake

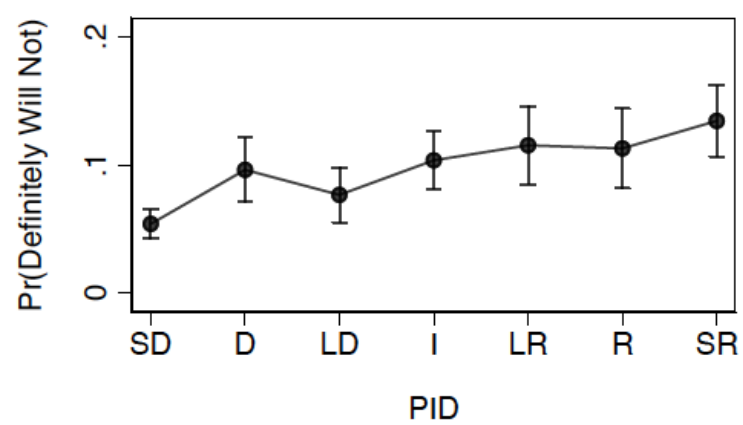

Vaccine Recommendation

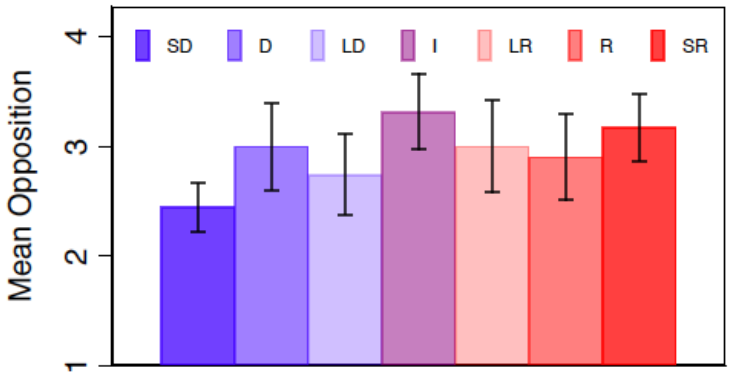

Vaccine Recommendation

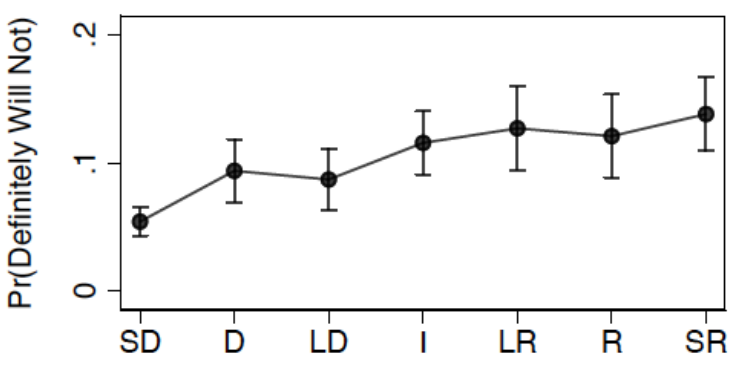

PID

Note. Top panels present mean levels of intended vaccine refusal (outcome variable $A$ in Table 1) and opposition to recommending the vaccine to others (outcome variable B in Table 2) across levels of partisan self-identification. 95\% confidence intervals presented. Analyses are limited to the control condition, to avoid the possibility to experimental contamination effects. The bottom panels present predicted levels of refusal and opposition to recommendation (again, with 95\% confidence intervals presented). Results are derived from multivariate ordered logistic regression models (please see the Supplementary Materials for full model output) which hold all covariates at their sample means. 
For robustness, I show (in non-pre-registered analyses) that the effects of PID on cancer vaccine uptake intentions and recommendations hold in multivariate ordered logistic regression models that control for attitudes toward scientific expertise (which has been shown to be associated with vaccine rejection; e.g., Sturgis et al., 2021; Callaghan et al., 2021; Lunz-Trujillo \& Motta 2021; Motta 2021), whether or not respondents have been previously diagnosed with cancer, and a series of demographic controls (educational attainment, age, racial identity, and gender identity). These analyses are presented in the bottom half of Figure 1 as the predicted probability of expressing the strongest observed levels of vaccine refusal for each outcome variable. There, I again document that increased strength of affiliation with the GOP is positively and significantly associated with vaccine rejection. Full model output is available in the Supplementary Materials.

Taken together, the findings presented thus far offer strong evidence that Republicans are more likely than Democrats to hold negative views toward personalized cancer vaccination. In what follows, I offer a series of empirical tests assessing whether or not how politicians' might eventually talk about cancer vaccines further influences uptake and/or recommendation intentions.

The Effect of Partisan Cues on Personal Vaccine Uptake.

Having documented a clear partisan asymmetry in personalized cancer vaccine uptake and encouragement, I next test whether or not partisans' willingness to vaccinate and/or encourage others to vaccinate are receptive to partisan elites' efforts to claim credit for advances in cancer vaccine development. Table 2 presents the results of six pre-registered multivariate ordered logistic regression models models regressing each of the two outcome variables (Models 1-4), as well as an additive index of the two ( $a=0.92$; re-scaled to range from 0-1) via OLS (Models 5-6), on the interaction between experimental treatment assignment and PID.

As noted in the pre-analysis plan, Table 2 offers two versions of each model. One set treats each level of PID as a separate interaction (Models $1,3,5$ ) to assess potential non-linearities in experimental treatment effects. The other set (Models 2, 4, 6) treats PID as a single quantity and estimate just one interaction per treatment, in order to offer a more-parsimonious investigation of treatment effects. As formal balance tests included in the supplementary materials indicate no significant differences in experimental treatment assignment partisan identity, age, gender, racial, or education across treatment groups, I do not control for any additional variables in these models.

Table 2. The Effect of Partisan Credit Claiming Cues on Vaccine Attitudes

$\begin{array}{lllllll} & \begin{array}{l}\text { Uptake } \\ \text { O. Logit }\end{array} & \begin{array}{l}\text { Uptake } \\ \text { O. Logit }\end{array} & \begin{array}{l}\text { Rec. } \\ \text { O. Logit }\end{array} & \begin{array}{l}\text { Rec. } \\ \text { O. Logit }\end{array} & \begin{array}{l}\text { Index } \\ \text { OLS }\end{array} & \begin{array}{l}\text { Index } \\ \text { OLS }\end{array} \\ \text { Dem. Cue } & -0.24 & -0.29+ & -0.01 & -0.16 & -0.02 & -0.04 \\ & -0.2 & -0.16 & -0.2 & -0.16 & -0.03 & -0.03\end{array}$




\begin{tabular}{|c|c|c|c|c|c|c|}
\hline \multirow[t]{2}{*}{ GOP Cue } & 0.16 & 0.15 & 0.24 & 0.22 & 0.04 & 0.03 \\
\hline & -0.2 & -0.17 & -0.21 & -0.17 & -0.03 & -0.03 \\
\hline \multirow[t]{2}{*}{$P I D=D$} & $0.81 *$ & - & $0.81 *$ & - & $0.12 *$ & - \\
\hline & -0.27 & & -0.28 & & -0.05 & \\
\hline \multirow[t]{2}{*}{$P I D=L D$} & 0.23 & - & $0.53+$ & - & 0.04 & - \\
\hline & -0.28 & & -0.28 & & -0.05 & \\
\hline \multirow[t]{2}{*}{$P I D=1$} & $0.88^{*}$ & - & $1.11^{*}$ & - & $0.16^{*}$ & - \\
\hline & -0.23 & & -0.24 & & -0.04 & \\
\hline \multirow[t]{2}{*}{$P I D=L R$} & $0.70^{*}$ & - & $0.78^{*}$ & - & $0.11^{*}$ & - \\
\hline & -0.3 & & -0.29 & & -0.05 & \\
\hline \multirow[t]{2}{*}{$P I D=R$} & $0.64 *$ & - & $0.66^{*}$ & - & $0.10^{*}$ & - \\
\hline & -0.28 & & -0.28 & & -0.05 & \\
\hline \multirow[t]{2}{*}{$\mathrm{PID}=\mathrm{SR}$} & $0.83^{*}$ & - & $1.00 *$ & - & $0.14^{*}$ & - \\
\hline & -0.22 & & -0.22 & & -0.04 & \\
\hline \multirow[t]{2}{*}{ Dem X D } & -0.12 & - & -0.33 & - & -0.04 & - \\
\hline & -0.38 & & -0.38 & & -0.06 & \\
\hline \multirow[t]{2}{*}{ Dem X LD } & 0.07 & - & -0.32 & - & -0.01 & - \\
\hline & -0.39 & & -0.39 & & -0.06 & \\
\hline \multirow[t]{2}{*}{ Dem X I } & 0.29 & - & 0.07 & - & 0.03 & - \\
\hline & -0.33 & & -0.33 & & -0.05 & \\
\hline \multirow[t]{2}{*}{ Dem X LR } & 0.61 & - & 0.61 & - & 0.11 & - \\
\hline & -0.4 & & -0.4 & & -0.07 & \\
\hline \multirow[t]{2}{*}{ Dem X R } & $0.80+$ & - & 0.55 & - & $0.12+$ & - \\
\hline & -0.41 & & -0.4 & & -0.07 & \\
\hline \multirow[t]{2}{*}{ Dem X SR } & $0.71 *$ & - & 0.47 & - & $0.11 *$ & - \\
\hline & -0.32 & & -0.32 & & -0.05 & \\
\hline \multirow[t]{2}{*}{ GOP X D } & -0.13 & - & -0.18 & - & -0.02 & - \\
\hline & -0.38 & & -0.38 & & -0.06 & \\
\hline \multirow[t]{2}{*}{ GOP X LD } & 0.09 & - & -0.1 & - & 0.01 & - \\
\hline & -0.4 & & -0.4 & & -0.07 & \\
\hline
\end{tabular}




\begin{tabular}{|c|c|c|c|c|c|c|}
\hline \multirow[t]{2}{*}{ GOP XI } & -0.37 & - & -0.49 & - & $-0.09+$ & - \\
\hline & -0.33 & & -0.34 & & -0.05 & \\
\hline \multirow[t]{2}{*}{ GOP X LR } & -0.32 & - & -0.42 & - & -0.09 & - \\
\hline & -0.4 & & -0.4 & & -0.07 & \\
\hline \multirow[t]{2}{*}{ GOP X R } & 0.13 & - & 0.2 & - & 0.02 & - \\
\hline & -0.4 & & -0.4 & & -0.07 & \\
\hline \multirow[t]{2}{*}{ GOP X SR } & -0.17 & - & -0.46 & - & -0.04 & - \\
\hline & -0.32 & & -0.33 & & -0.05 & \\
\hline \multirow[t]{2}{*}{ PID (Intervalized) } & - & $0.74^{*}$ & - & $0.87^{*}$ & - & $0.13^{*}$ \\
\hline & & -0.2 & & -0.2 & & -0.03 \\
\hline \multirow[t]{2}{*}{ Dem X PID } & - & $0.84 *$ & - & $0.66 *$ & - & $0.13^{*}$ \\
\hline & & -0.29 & & -0.28 & & -0.05 \\
\hline \multirow[t]{2}{*}{ GOP X PID } & - & -0.19 & - & -0.38 & - & -0.04 \\
\hline & & -0.28 & & -0.29 & & -0.05 \\
\hline \multirow[t]{2}{*}{ BO } & - & - & - & - & $0.29 *$ & $0.32 *$ \\
\hline & & & & & -0.02 & -0.02 \\
\hline \multirow[t]{2}{*}{$\mathrm{t} 1$} & $-0.77^{*}$ & $-0.93^{*}$ & $-0.72 *$ & $-0.92 *$ & - & - \\
\hline & -0.14 & -0.12 & -0.14 & -0.12 & & \\
\hline \multirow[t]{2}{*}{ t2 } & $0.39 *$ & $0.22+$ & $0.40^{*}$ & 0.18 & - & - \\
\hline & -0.14 & -0.12 & -0.14 & -0.12 & & \\
\hline \multirow[t]{2}{*}{ t3 } & $1.43^{*}$ & $1.24^{*}$ & $1.49 *$ & $1.26^{*}$ & - & - \\
\hline & -0.14 & -0.12 & -0.14 & -0.12 & & \\
\hline \multirow[t]{2}{*}{$\mathrm{t} 4$} & $2.20^{*}$ & $2.01 *$ & $2.37^{*}$ & $2.13^{*}$ & - & - \\
\hline & -0.15 & -0.13 & -0.15 & -0.13 & & \\
\hline \multirow[t]{2}{*}{ t5 } & $2.87^{*}$ & $2.68^{*}$ & $2.93^{*}$ & $2.69 *$ & - & - \\
\hline & -0.16 & -0.14 & -0.16 & -0.14 & & \\
\hline$N$ & 1690 & 1690 & 1690 & 1690 & 1690 & 1690 \\
\hline
\end{tabular}

Note. Ordered logistic and OLS regression coefficients presented, with standard errors in parentheses. Please see the description in text for additional information about these models. For reference, the quantities referenced in text in application to testing Hypothesis 2 are bolded. 
Table 2 offers strong support for $\mathrm{H} 2 \mathrm{a}$, with respect to personal vaccine uptake. When presented with the Democratic Cue described in Table 1 (vs. the control), I find that Strong Republicans (Model 1) were significantly more likely to indicate that they would intend to refuse personalized cancer vaccination for themselves $(B=0.71[0.08,1.34], p<0.05)$ than Strong Democrats (omitted as an analytic baseline). I find an analogous pattern of effects when interacting the full PID scale - scored such that an increase indicates stronger levels of affiliation with the GOP (and rescaled to range from 0-1) - with experimental treatment assignment. Moving across the PID scale is associated with a statistically significant increase in intentions to refuse vaccination for oneself $(B=0.84[0.28,1.40], p<0.05)$.

Table 2 also offers support for $\mathrm{H} 2 \mathrm{~b}$, which anticipated that the presence of GOP cues might neutralize partisan differences in anticipated vaccine uptake. There, I find that the interaction between GOP cue assignment (vs. the control) and strong self-identification with the GOP (Model $1 ; B=-0.17[-0.80,0.46]$, $p=n . s$.) as well as the full PID scale (Model 2; $B=-0.19[-0.74,0.37], p=n . s$.) is both negatively signed and fails to attain conventional levels of statistical significance. This suggests that Republicans are comparatively less likely to intend to refuse vaccination when presented with a GOP cue, compared to when they are presented with a Democratic credit claiming for cancer vaccine research (RQ1).

Note, however, that the substantive differences I observe when testing $\mathrm{H} 2 \mathrm{~b}$ across treatments fail to attain conventional levels of two-tailed significance, as indicated by overlapping confidence intervals across treatment for Strong Republicans. This means that while the GOP cue improved vaccination intentions on the right, the magnitude of these effects (1) is not sufficient to erase baseline levels of partisan disagreement regarding vaccine uptake (i.e., as evidenced by the non-significant comparison to the control condition), and (2) does not offer a reduction in polarization that is statistically differentiable from zero when compared to the Democratic cue condition.

Note also that I fail to observe any statistically significant evidence of backlash among Democrats in the multivariate models (RQ2). Consequently, while I find strong evidence of neutralization $(\mathrm{H} 2 \mathrm{~b})$, it is unclear from the models presented in the Table whether or not these effects are primarily due to Republicans' acceptance or Democrats' rejection of GOP endorsement cues (although most available evidence points to the former as more likely, as described above).

Recognizing the difficulties associated with deriving substantively meaningful interpretations from interactive coefficients alone, Figure 2 presents the predicted probability of either indicating that respondents "almost certainly would" (top panels) or "almost certainly would not" (bottom panels) receive a personalized cancer vaccine. The left hand side of the figure presents nonlinear effects (i.e., estimates derived from Model 1 ) and the right hand side presents linear effects (i.e., the results derived from Model 2). Connected lines correspond to treatment effects across experimental conditions, and across levels of PID. For ease of visual interpretation, and because the GOP treatment did not yield any statistically meaningful interactive effects I provide $95 \%$ confidence intervals for the Democratic Cue treatment only. 
Figure 2. The Effect of Partisan Credit Claiming Cues on Vaccine Attitudes
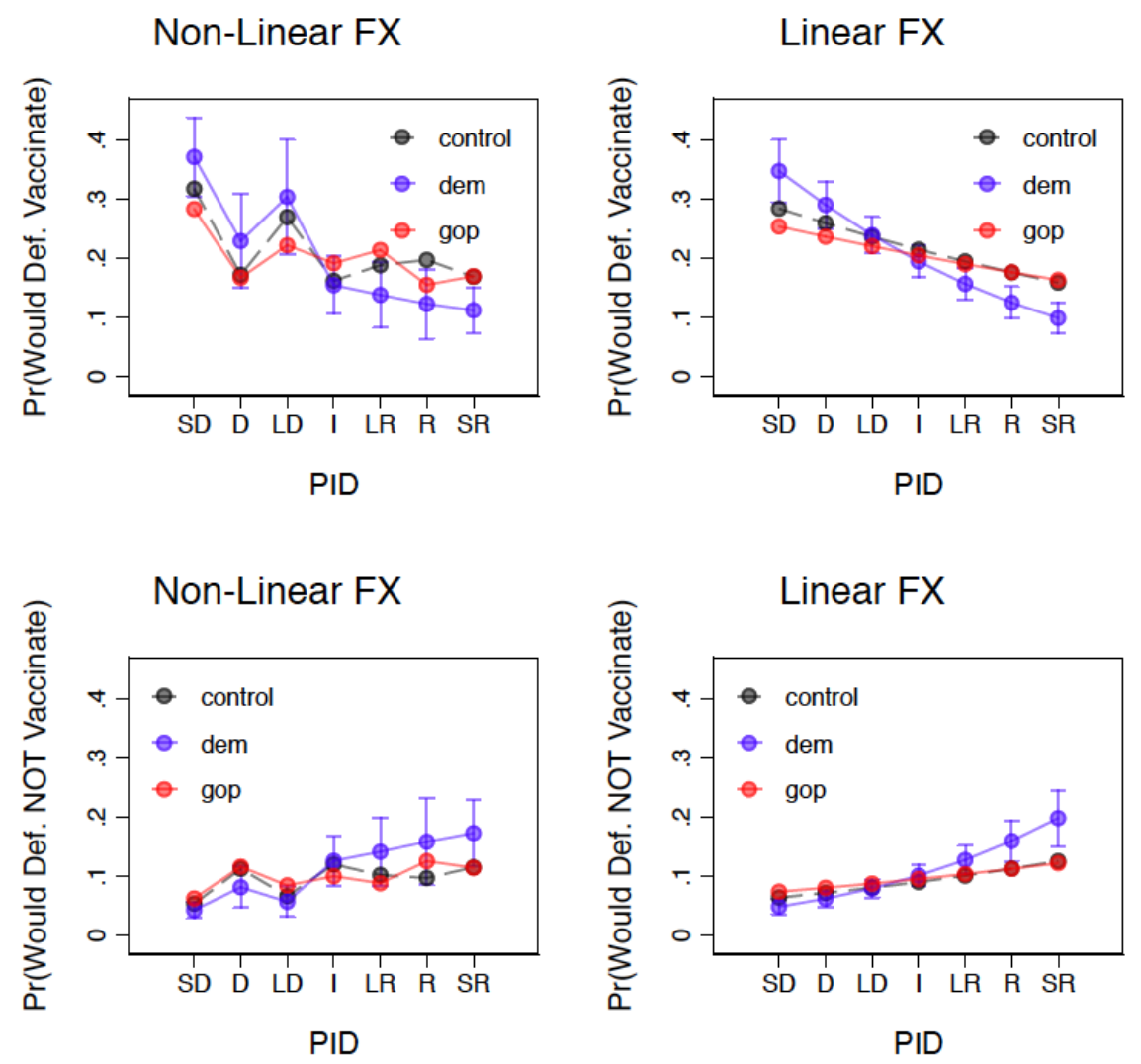

Note. Figures present the predicted probability of definitely (top rows) intending to vaccinate (outcome variable A in Table 1) or recommend vaccination (outcome variable B in Table 1) via personalized cancer vaccines, as well as the probability of definitely not taking each of these actions (bottom rows). Non-linear effects are derived from Model 1 in Table 2, whereas linear effects are derived from Model 2. All predictions hold all other covariates presented in Table 2 at their sample means.

The results again offer strong support for my theoretical expectations. Turning first to the top half of the figure, I find that stronger identification with the GOP is associated with comparatively stronger declines (relative to the control condition) in the likelihood that one would definitely choose to vaccinate. I observe monotonic decreases in uptake intentions for self-identified Republicans in both the nonlinear and linear estimation strategies (i.e., by moving from left-to-right from the mid-point of the $x$ axis); with the important note that Democrats and Independents display comparatively higher, yet non-monotonic, increases in vaccine intention irrespective of frame (i.e., by moving from right-to-left from the mid-point of the $x$ axis). I observe an analogous pattern in the bottom half of the figure, such that increases in the strength of identification with the GOP is associated with monotonic increases in the likelihood that respondents will definitely not vaccinate; irrespective of estimation strategy.

In both cases, the magnitude of these effects are also substantively large. Whereas the likelihood that Strong Republicans would choose to vaccinate is $17 \%$ in the control condition in the non-linear 
estimation, and $16 \%$ in the linear estimation, those quantities fall to $11 \%$ and $10 \%$ respectively when exposed to information about the role that Joe Biden played in securing funding for cancer research. Likewise, the probability that Strong Republicans choose to forego vaccination is just $11 \%$ (non-linear) and $12 \%$ (linear) in the control group, compared to $17 \%$ and $20 \%$ (respectively) when exposed to the Democratic cue.

\section{The Effect of Partisan Cues on Vaccine Recommendation.}

While the results presented thus far offer clear support for my theoretical expectations, I find a more-mixed pattern of results when turning to whether or not people would recommend that someone else receive a personalized cancer vaccine. As Table 2 indicates, I find no statistically significant evidence of an interactive effect of experimental treatment assignment across PID in the non-linear estimation strategy (Model 3). However, I detect a somewhat smaller treatment effect - in comparison to the uptake models - of the Democratic cue across the PID scale in the linear estimation approach presented in Model 4 ( $B=0.66[0.11,1.22], p<0.05)$.

This pattern of results offers mixed support for $\mathrm{H} 2 \mathrm{a}$. Consequently, I do not probe the corresponding interactive terms to assess substantive effects (as Brambor et al., 2004 recommend).

Moreover, although I hesitate to offer post hoc speculation as to why I observe strong support with respect to personal vaccine uptake, and more mixed support with respect to recommending vaccines to others, it may be the case that individual liberty concerns play a moderating role. Republicans are more likely than Democrats to view vaccination as a personal choice (Kahan 2010; Hornsey et al., 2018). Correspondingly, while their partisan distaste for Joe Biden might color their own willingness to vaccinate, self-identified Republicans may not necessarily extend that reasoning to their views of what others ought to do. The precise mechanism by which the asymmetry between personal and others' vaccination uptake occurs is an important direction for future research.

Finally, given the strong levels of support for $\mathrm{H} 2 \mathrm{a}$ I observed with respect to the uptake outcome variable, and positive (yet more-mixed) evidence for the recommendation outcome - as well the idea that multiple-item indices tend to reduce random measurement error that might increase the probability of committing Type II error in inferential models (Ansolabehere, Rodden, \& Snyder 2008) - it is perhaps unsurprising that pooling the two outcome variables together (Models 5 and 6) offers support for my theoretical predictions. In both the non-linear $(B=0.11[0.01,0.21], p<0.05)$ and linear $(B=0.13[0.02$, 0.22], $\mathrm{p}<0.05$ ) estimation approaches, I find that Strong Republicans (Model 5) and increases in GOP partisan identification (Model 6) are associated with an increased tendency to hold negative views toward personal cancer vaccination in the Democratic cue condition (vs. the control).

\section{Conclusion \& Discussion}

Taken together, the results presented in this paper document the possibility that even the possibility of

"curing cancer" - i.e., the potential to combat one of the leading causes of death in the United States, 
which touches the lives of Democrats, Republicans, and Independents alike - is not immune from partisan politics. I find that Democrats are more likely than Republicans to both intend to receive personalized cancer vaccines, and to recommend that others do the same. When Democrats take credit for playing a role in funding cancer research, I further demonstrate that Republicans are significantly more likely to forego vaccination themselves (although not necessarily less likely to recommend that others pursue vaccination), compared to when funding cancer research is presented as a bi-partisan effort. GOP credit claiming for cancer funding research improves vaccine attitudes on the right, but does not erase existing partisan asymmetries we might otherwise observe in the absence of directional partisan cues.

These sobering findings have the potential to inform effective political and health communication about cancer vaccination, with an eye toward increasing vaccine uptake. If and when personalized cancer vaccines (and perhaps other cancer preventatives/therapeutics) are ultimately deemed safe and effective for public use, ensuring sufficiently high levels of uptake will be essential for resolving one of the greatest public health crises of our time.

My research suggests two potential ways to avoid politicizing cancer vaccines. Perhaps the simplest is to avoid linking politicians - either directly, via political elites claiming credit for cancer research funding, or indirectly by mentioning elites in conjunction with the funding that made research advances possible (as was done in the study's experimental treatments) - to medical breakthroughs like personalized cancer vaccines. Recognizing the possibility of asymmetric cancer vaccine hesitancy on the right, a more-complex approach might be to encourage GOP politicians to take an active role in lending their political support to these vaccines.

Of course, this work is not without important limitations. Chief among them is the fact that this is a "single shot" survey experiment, which is necessarily limited in both the "target" politicians it employs as source cues, as well as the content of the message presented to survey participants. Whether or not messaging strategies varying some or all of these elements might lead us to draw similar conclusions is an important area for future research.

Moreover, while we should not necessarily expect the direction or magnitude of experimental treatment effects to be different in non-probability samples of the American public than we otherwise would in more-representative surveys, it is important to point out that base rate levels of vaccine acceptance across partisan identification may be biased by sample composition. I therefore hesitate to generalize specific point estimates of mean levels vaccine acceptance to the US adult population, focusing instead on the directional nature and statistical significance of these effects. I look forward to efforts to replicate this work in more-representative samples, in the future. 


\section{References}

Amin, A. B., Bednarczyk, R. A., Ray, C. E., Melchiori, K. J., Graham, J., Huntsinger, J. R., \& Omer, S. B. (2017). Association of moral values with vaccine hesitancy. Nature Human Behaviour, 1(12), 873-880.

Ansolabehere, S., Rodden, J., \& Snyder, J. M. (2008). The strength of issues: Using multiple measures to gauge preference stability, ideological constraint, and issue voting. American Political Science Review, 102(2), 215-232.

Aronow, P. M., Kalla, J., Orr, L., \& Ternovski, J. (2020). Evidence of rising rates of inattentiveness on Lucid in 2020.

Blass, E., \& Ott, P. A. (2021). Advances in the development of personalized neoantigen-based therapeutic cancer vaccines. Nature Reviews Clinical Oncology, 18(4), 215-229.

Callaghan, T., Moghtaderi, A., Lueck, J. A., Hotez, P., Strych, U., Dor, A., ... \& Motta, M. (2021). Correlates and disparities of intention to vaccinate against COVID-19. Social Science \& Medicine (1982).

Clifford, S., \& Wendell, D. G. (2016). How disgust influences health purity attitudes. Political Behavior, 38(1), 155-178.

Coppock, A., \& McClellan, O. A. (2019). Validating the demographic, political, psychological, and experimental results obtained from a new source of online survey respondents. Research \& Politics, 6(1), 2053168018822174.

Diamond, D. (2020). FDA shake-up continues as another comms official removed from top role. Politico. https://www.politico.com/news/2020/09/02/fda-shake-up-comms-team-407688

Enders, A. M., Uscinski, J. E., Klofstad, C., \& Stoler, J. (2020). The different forms of COVID-19 misinformation and their consequences. The Harvard Kennedy School Misinformation Review.

Fauzia, M. (2021). Fact check: Comparison between COVID-19 and cancer death rate misleading. USA Today.

https://www.usatoday.com/story/news/factcheck/2021/05/21/fact-check-comparison-between -covid-19-cancer-death-rate-misleading/4991452001/

Gadarian, S. K., Goodman, S. W., \& Pepinsky, T. B. (2021). Partisanship, health behavior, and policy attitudes in the early stages of the COVID-19 pandemic. Plos one, 16(4), e0249596.

Garcia, L. L., \& Yap, J. F. C. (2021). The role of religiosity in COVID-19 vaccine hesitancy. Journal of Public Health.

Gauchat, G. (2012). Politicization of science in the public sphere: A study of public trust in the United States, 1974 to 2010. American sociological review, 77(2), 167-187.

Grossman, G., Kim, S., Rexer, J. M., \& Thirumurthy, H. (2020). Political partisanship influences behavioral responses to governors' recommendations for COVID-19 prevention in the United States. Proceedings of the National Academy of Sciences, 117(39), 24144-24153.

Hornsey, M. J., Harris, E. A., \& Fielding, K. S. (2018). The psychological roots of anti-vaccination attitudes: A 24-nation investigation. Health psychology, 37(4), 307.

Iyengar, S., Lelkes, Y., Levendusky, M., Malhotra, N., \& Westwood, S. J. (2019). The origins and consequences of affective polarization in the United States. Annual Review of Political Science, $22,129-146$. 
Jamieson, K. H., \& Albarracin, D. (2020). The Relation between Media Consumption and Misinformation at the Outset of the SARS-CoV-2 Pandemic in the US. The Harvard Kennedy School Misinformation Review.

Jerit, J., \& Zhao, Y. (2020). Political misinformation. Annual Review of Political Science, 23, 77-94.

Kahan, D. (2010). Fixing the communications failure. Nature, 463(7279), 296-297.

Kraft, P. W., Lodge, M., \& Taber, C. S. (2015). Why people "don't trust the evidence" motivated reasoning and scientific beliefs. The ANNALS of the American Academy of Political and Social Science, 658(1), 121-133.

Lenz, G. S. (2013). Follow the leader?: how voters respond to politicians' policies and performance. University of Chicago Press.

Kahan, D. M. (2017). On the sources of ordinary science knowledge and extraordinary science ignorance. The Oxford handbook of the science of science communication, 35, 35-50.

Kaiser, J., \& Couzin-Frankel, J. (2016). Biden seeks clear course for his cancer moonshot. Science.

Karlin-Smith. S. (2016). Biden's farewell gift: Cancer moonshot helps pass $\$ 6.3$ billion research bill. Politico. https://www.politico.com/story/2016/12/joe-biden-cancer-moonshot-bill-232342

Kunda, Z. (1990). The case for motivated reasoning. Psychological bulletin, 108(3), 480.

Krosnick, J. A. (1991). Response strategies for coping with the cognitive demands of attitude measures in surveys. Applied cognitive psychology, 5(3), 213-236.

Lindholt, M. F., Jørgensen, F. J., Bor, A., \& Petersen, M. B. (2020). Willingness to use an approved COVID-19 vaccine: cross-national evidence on levels and individual-level predictors. PsyArXiv. November, 27.

Lunz Trujillo, K., Motta, M., Callaghan, T., \& Sylvester, S. (2021). Correcting misperceptions about the MMR vaccine: using psychological risk factors to inform targeted communication strategies. Political Research Quarterly, 74(2), 464-478.

Mason, L. (2015). "I disrespectfully agree": The differential effects of partisan sorting on social and issue polarization. American Journal of Political Science, 59(1), 128-145.

Mason, L. (2018). Uncivil agreement: How politics became our identity. University of Chicago Press.

McCarthy, M. (2016). US president endorses" moonshot" effort to cure cancer. BMJ: British Medical Journal (Online), 352.

Merkley, E., \& Loewen, P. J. (2021). Anti-intellectualism and the mass public's response to the COVID-19 pandemic. Nature Human Behaviour, 5(6), 706-715.

Miller, J. M. (2020). Psychological, political, and situational factors combine to boost COVID-19 conspiracy theory beliefs. Canadian Journal of Political Science/Revue canadienne de science politique, 53(2), 327-334.

Motta, M. (2018). The dynamics and political implications of anti-intellectualism in the United States. American Politics Research, 46(3), 465-498.

Motta, M., Stecula, D., \& Farhart, C. (2020). How right-leaning media coverage of COVID-19 facilitated the spread of misinformation in the early stages of the pandemic in the US. Canadian Journal of Political Science/Revue canadienne de science politique, 53(2), 335-342.

Motta, M. (2020). Could concern about climate change increase demand for a Lyme disease vaccine in the US?. Vaccine, 38(40), 6191-6193. 
Motta, M. (2021). Can a COVID-19 vaccine live up to Americans' expectations? A conjoint analysis of how vaccine characteristics influence vaccination intentions. Social Science \& Medicine, 272, 113642.

Motta, M. (2021). Republicans, Not Democrats, Are More Likely to Endorse Anti-Vaccine Misinformation. American Politics Research, 1532673X211022639.

Motta, M., \& Goren, P. (2021). Basic human values \& compliance with government-recommended prosocial health behavior. Journal of Elections, Public Opinion and Parties, 31(sup1), 206-217.

Naher, D. (2016). State of the Union 2016: Obama endorses Biden's cancer research 'moonshot'. STAT News. https://www.statnews.com/2016/01/12/obama-biden-cancer-moonshot/

Nyhan, B., Reifler, J., Richey, S., \& Freed, G. L. (2014). Effective messages in vaccine promotion: a randomized trial. Pediatrics, 133(4), e835-e842.

Oliver, J. E., \& Wood, T. (2014). Medical conspiracy theories and health behaviors in the United States. JAMA internal medicine, 174(5), 817-818.

Peterson, E., Goel, S., \& Iyengar, S. (2021). Partisan selective exposure in online news consumption: Evidence from the 2016 presidential campaign. Political Science Research and Methods, 9(2), 242-258.

Peyton, K., Huber, G. A., \& Coppock, A. (2020). The generalizability of online experiments conducted during the COVID-19 pandemic.

Schattner, E. (2015). Memo To Candidates: Support For U.S. Cancer Research Crosses Party Lines. Forbes. https://www.forbes.com/sites/elaineschattner/2015/09/16/memo-to-candidates-aacr-poll-find s-broad-u-s-public-support-for-federal-funding-of-cancer-research/?sh=c2efe0532c07

Singer, D. S., Jacks, T., \& Jaffee, E. (2016). A US “Cancer Moonshot” to accelerate cancer research. Science, 353(6304), 1105-1106.

Stecula, D. A., \& Pickup, M. (2021). How populism and conservative media fuel conspiracy beliefs about COVID-19 and what it means for COVID-19 behaviors. Research \& Politics, 8(1), 2053168021993979.

Stroud, N. J. (2011). Niche news: The politics of news choice. Oxford University Press on Demand.

Sturgis, P., Brunton-Smith, I., \& Jackson, J. (2021). Trust in science, social consensus and vaccine confidence. Nature Human Behaviour, 1-7.

Uscinski, J. E., Enders, A. M., Klofstad, C., Seelig, M., Funchion, J., Everett, C., ... \& Murthi, M. (2020). Why do people believe COVID-19 conspiracy theories?. Harvard Kennedy School Misinformation Review, 1(3).

Viswanath, K., Bekalu, M., Dhawan, D., Pinnamaneni, R., Lang, J., \& McLoud, R. (2021). Individual and social determinants of COVID-19 vaccine uptake. BMC Public Health, 21(1), 1-10.

Webster, S. W. (2020). American rage: How anger shapes our politics. Cambridge University Press.

West, E. A., \& lyengar, S. (2020). Partisanship as a social identity: Implications for polarization. Political Behavior, 1-32. 